\title{
¿Es posible crear sociedades de economía mixta para la gestión de servicios públicos locales en el marco de contratos de servicios y de concesión de servicios? ${ }^{1}$
}

\section{Is it possible to create mixed-economy companies to manage local public services in the framework of service contracts and service concessions?}

\author{
Diana Santiago Iglesias \\ Universidad de Santiago de Compostela (España) \\ ORCID: http://orcid.org/0000-0001-5017-8219 \\ diana.santiago@usc.es
}

\section{NOTA BIOGRÁFICA}

Profesora contratada doctora de Derecho Administrativo en la Universidad de Santiago de Compostela. Su actividad investigadora se centra en las siguientes líneas: Derecho local; Derecho de la contratación pública; Justicia administrativa; Servicios públicos.

\section{RESUMEN}

Las sociedades de economía mixta han sido utilizadas tradicionalmente como formas de gestión de servicios públicos en el ámbito local. Suprimido el contrato de gestión de servicios públicos, del cual constituían una modalidad, el objeto de este trabajo consiste en analizar si continúa siendo posible emplear esta fórmula para gestionar servicios públicos locales tras la entrada en vigor de la Ley 9/2017, de 8 de noviembre, de contratos del sector público. En concreto, se trata de determinar si se puede crear este tipo de sociedades en el marco de los contratos de concesión de servicios y de los contratos de servicios, fórmulas contractuales previstas en la nueva norma para canalizar la gestión de servicios públicos.
\end{abstract}

\section{PALABRAS CLAVE}

Sociedades de economía mixta; gestión de servicios públicos locales; contrato de servicios; concesión de servicios; derecho de la contratación pública.

\begin{abstract}
Mixed-economy companies have traditionally been used as forms of public services management at the local level. Since the deletion of the «public services management contract», -of which they were a modality-, the object of this work is to assess whether it is still possible to use this formula to manage local public services after the entry into force of Law 9/2017, of 8 November, about the public sector contracts.
\end{abstract}

1 Este trabajo ha sido realizado en el marco de la ayuda de la Consellería de Educación, Universidade e Formación Profesional y la Consellería de Economía, Emprego e Industria de la Xunta de Galicia, para la consolidación y estructuración de unidades de investigación, concedida al grupo de investigación de la Universidad de Santiago de Compostela GI-1876 "Empresa y Administración", Grupo de Referencia Competitiva del Sistema Universitario de Galicia - ED431C 2019/15 y del proyecto de investigación: Instrumentos jurídicos para la lucha contra la despoblación en el ámbito rural (DESPORU), Ref.: RTI2018-099804-A-100. Financiado por: FEDER/ Ministerio de Ciencia, Innovación y Universidades, Agencia Estatal de Investigación. Gobierno de España. 
REALA. Nueva Época - N. ${ }^{16}$, octubre 2021 - ISSN: 1989-8975 - DOI: https://doi.org/10.24965/reala.i16.10965 - [Págs. 98-117]

¿Es posible crear sociedades de economía mixta para la gestión de servicios públicos locales en el marco de contratos de servicios..

Diana Santiago Iglesias

In particular, it wants to clarify if this companies can be created under the framework of service contracts and service concessions, namely the types of contracts provided for in the new legislation to manage public services.

\title{
KEYWORDS
}

Mixed-economy companies; management of local public services; service contract; service concession; public procurement law.

\begin{abstract}
SUMARIO
1. PLANTEAMIENTO. 2. ALGUNAS CUESTIONES PREVIAS: LAS FORMAS DE GESTIÓN INDIRECTA DE LOS SERVICIOS PÚBLICOS LOCALES TRAS LA LEY 9/2017. 2.1. FÓRMULAS CONTRACTUALES DE GESTIÓN DE LOS SERVICIOS PÚBLICOS. 2.2. EL ENCAJE DE LAS ANTIGUAS MODALIDADES DEL CONTRATO DE GESTIÓN DE SERVICIOS PÚBLICOS EN LA LCSP DE 2017. 3. ¿PUEDEN EMPLEARSE LAS SOCIEDADES DE ECONOMÍA MIXTA PARA LA GESTIÓN DE SERVICIOS PÚBLICOS TRAS LA LEY 9/2017, 8 DE NOVIEMBRE, DE CONTRATOS DEL SECTOR PÚBLICO? 3.1. PREMISAS. 3.1.1. Primera premisa: las sociedades de economía mixta creadas para la gestión contractual de servicios públicos son una fórmula de colaboración público-privada institucionalizada con personalidad jurídico-privada y un régimen jurídico mixto. 3.1.2. Segunda premisa: la selección del socio privado ha de realizarse a través de un procedimiento de concurrencia competitiva. 3.1.3. Tercera premisa: en las sociedades de economía mixta creadas ex novo el acto de selección del socio privado va acompañado de la creación de la sociedad de economía mixta y de la atribución a la misma de la gestión del servicio público. 3.1.4. Cuarta: la supresión del contrato de gestión de servicios públicos no impide el recurso a la sociedad de economía mixta como fórmula gestora ni exige la celebración de una doble licitación para la adjudicación del servicio de que se trate. 3.2. UNA POSIBLE RESPUESTA: LAS SOCIEDADES DE ECONOMÍA MIXTA CONTINÚAN SIENDO UNA FÓRMULA DE GESTIÓN DE SERVICIOS PÚBLICOS TRAS LA LCSP DE 2017. 4. LÍMITES AL EMPLEO DE LAS SOCIEDADES DE ECONOMÍA MIXTA PARA LA GESTIÓN DE SERVICIOS PÚBLICOS. 4.1. LÍMITES DERIVADOS DE LA DISPOSICIÓN ADICIONAL VIGESIMOSEGUNDA DE LA LCSP DE 2017. 4.1.1. Origen de la disposición adicional vigesimosegunda de la LCSP de 2017. 4.1.2. Alcance de la disposición adicional vigesimosegunda de la LCSP de 2017. 4.2. LÍMITES DERIVADOS DE LA MODIFICACIÓN DE LA LBRL INTRODUCIDA POR LA LEY 27/2013, DE 27 DE DICIEMBRE, DE RACIONALIZACIÓN Y SOSTENIBILIDAD DE LA ADMINISTRACIÓN LOCAL. 5. REFLEXIÓN FINAL. REFERENCIAS BIBLIOGRÁFICAS.
\end{abstract}

\section{PLANTEAMIENTO}

Tras la supresión del contrato de gestión de servicios públicos, entre cuyas modalidades se encontraban las sociedades de economía mixta, se ha planteado si continúa siendo posible recurrir a esta fórmula para su gestión, la cual ha demostrado múltiples ventajas, especialmente, en contextos de crisis económica, al permitir a los entes locales: mantener cierto control directo sobre la gestión del servicio público en cuestión; contar con la experiencia empresarial y de gestión del socio privado; obtener una fuente de financiación complementaria y, eventualmente, la obtención de beneficios con la erogación del mismo (Santiago Iglesias, 2010, p. 37).

La escueta regulación de las sociedades de economía mixta contenida en la nueva Ley 9/2017, de 8 de noviembre, de contratos del sector público (en adelante, LCSP de 2017) se reduce, fundamentalmente, a su disposición adicional vigesimosegunda, cuya redacción deja sin responder a la pregunta anterior e, incluso, añade, nuevos problemas interpretativos, al regular el régimen aplicable a este tipo de sociedades cuando se constituyen en el marco de contratos de concesión de obras y de concesión de servicios, de manera que no queda claro si sólo cabe recurrir a esta fórmula en el marco de dichos contratos o bien, si se trata de un régimen especial aplicable a estos supuestos en concreto.

Así las cosas, para responder a dichas cuestiones se realizará, con carácter previo, un análisis de los tipos contractuales que pueden emplearse para la gestión de servicios públicos locales de acuerdo con el nuevo marco normativo para, a continuación, examinar la posibilidad de llevar a cabo la ejecución de los mismos a través de sociedades de economía mixta y, en su caso, identificar los límites aplicables al recurso a esta figura por los entes locales. 
REALA. Nueva Época - N. ${ }^{16}$, octubre 2021 - ISSN: 1989-8975 - DOI: https://doi.org/10.24965/reala.i16.10965 - [Págs. 98-117]

\section{ALGUNAS CUESTIONES PREVIAS: LAS FORMAS DE GESTIÓN INDIRECTA DE LOS SERVICIOS PÚBLICOS LOCALES TRAS LA LEY 9/2017}

Los entes locales pueden decidir de forma discrecional el modo en el que gestionarán los servicios públicos de su titularidad ${ }^{2}$. El Derecho de la Unión Europea reconoce libertad a los Estados miembros a la hora de decidir la forma de gestión de sus servicios públicos. Este tema ha sido abordado, de nuevo, recientemente por la doctrina en el contexto del debate sobre las remunicipalizaciones (López de Castro y Ortega Bernardo, 2021, p. 490; Ortega Bernardo y de Sande, 2016, pp. 64-67; Ponce Solé, 2016, p. 84; Tornos Mas, 2016, pp. 41-49) ${ }^{3}$.

En el derecho interno, así se reconoce también, de un lado, en el artículo 86.2 de la Ley 7/1985, de 2 de abril, Reguladora de las Bases del Régimen Local (en adelante, LBRL), donde se señala que la decisión sobre la forma concreta en que se gestionará un determinado servicio corresponderá al pleno de la corporación y, de otro lado, en el artículo 30 del Decreto de 17 de junio de 1955, por el que se aprueba el Reglamento de Servicios de las Corporaciones locales (en adelante, $\mathrm{RSCL}$ ), donde se reconoce a los entes locales la «plena potestad para constituir, organizar, modificar y suprimir los servicios de su competencia».

Así, los entes locales podrán elegir la forma de gestión que prefieran de entre las establecidas en el art. 85 de la LBRL: a) gestión directa, por la propia entidad local, o bien, a través de un organismo autónomo local, entidad pública empresarial local o sociedad mercantil local íntegramente pública y b) gestión indirecta, remitiéndose, expresamente, con una técnica normativa cuestionable ${ }^{4}$, a las distintas formas previstas para el contrato de gestión de servicios públicos en el Texto Refundido de la Ley de Contratos del Sector Público, aprobado por Real Decreto Legislativo 3/2011, de 14 de noviembre (en adelante, TRLCSP).

No obstante, de acuerdo con la nueva redacción de dicho precepto introducida por la Ley 27/2013, de 27 de diciembre, de Racionalización y Sostenibilidad de la Administración Local (en adelante, LRSAL), la potestad discrecional atribuida a los entes locales se ha visto limitada. De un lado, se exige que la elección de la forma de gestión se base en criterios de sostenibilidad y eficiencia. De otro lado, se introducen importantes límites al recurso a determinadas fórmulas, pudiendo observarse cierta preferencia por la gestión directa por la propia entidad local o a través de un organismo autónomo local, y por la gestión indirecta, que no se sujeta a requisitos adicionales (Montoya Martín, 2014, p. 28).

Así, la gestión a través de una entidad pública empresarial o de una sociedad íntegramente pública queda condicionada a que se demuestre su mayor sostenibilidad y eficiencia respecto de las demás formas de gestión directa, para lo cual deberán tenerse en cuenta los criterios de rentabilidad económica y recuperación de la inversión.

Respecto de la gestión indirecta de los servicios públicos, como se ha dicho, la LBRL no ha introducido más limitaciones que las que, en su caso, puedan derivarse de la nueva disposición adicional novena de la LBRL, sobre la cual se volverá en los siguientes epígrafes, de manera que su estudio pasa, necesariamente, por el análisis de la normativa de contratos públicos. Como se ha indicado, el art. 85 de la LBRL se remite, en este punto, a las distintas formas previstas para el contrato de gestión de servicios públicos regulado en el TRLCSP. Dicha remisión, debe entenderse realizada a la vigente LCSP de 2017, la cual ha derogado el texto anterior y, a su vez, ha suprimido, sorprendentemente, el contrato de gestión de servicios públicos.

Así las cosas, cabe plantearse dos cuestiones: de un lado, qué fórmulas contractuales existen en la nueva ley para instrumentar la gestión indirecta de un servicio público y, de otro lado, cómo encajan las antiguas modalidades del contrato de gestión de servicios públicos en las mismas.

\subsection{Fórmulas contractuales de gestión de los servicios públicos}

Una de las novedades más llamativas introducidas por la nueva LCSP ha sido la supresión del contrato de gestión de servicios públicos -que constituía una categoría genuina de nuestro ordenamiento jurídico y desconocida desde el punto de vista del derecho de la Unión Europea-, decisión que ha sido criticada por

\footnotetext{
2 En este sentido, vid. la Sentencia del Tribunal Supremo, de 23 de mayo de 1997, Sala de lo Contencioso-Administrativo, Sección cuarta, recurso núm. 6813/1991.

3 Vid. el art. 2 de la Directiva 2014/23/UE del Parlamento Europeo y del Consejo, de 26 de febrero de 2014, relativa a la adjudicación de contratos de concesión, donde se reconoce el principio de libertad de administración de las autoridades públicas.

4 Hubiese sido más adecuado hacer referencia a la normativa reguladora de los contratos públicos en lugar de mencionar expresamente la norma de aplicación en el momento de redacción de dicho precepto.
} 
REALA. Nueva Época - N. ${ }^{16}$, octubre 2021 - ISSN: 1989-8975 - DOI: https://doi.org/10.24965/reala.i16.10965 - [Págs. 98-117]

¿Es posible crear sociedades de economía mixta para la gestión de servicios públicos locales en el marco de contratos de servicios..

Diana Santiago Iglesias

la doctrina por innecesaria desde el punto de vista de la adecuada transposición de las directivas de contratos públicos (Laguna de Paz, 2017, p. 44; Martínez López-Muñiz, 2017, p. 40). Así las cosas, a partir de la entrada en vigor de la LCSP de 2017, la gestión indirecta puede llevarse a cabo a través de dos fórmulas contractuales: el contrato de servicios y el contrato de concesión de servicios (Villarejo Galende y Calonge Velázquez, 2018, pp. 28-33). A continuación, se analizarán, brevemente, sus características principales.

De un lado, el contrato de concesión de servicios, de conformidad con lo dispuesto en el artículo 15 de la LCSP de 2017, se define como aquel en cuya virtud uno o varios poderes adjudicadores encomiendan a título oneroso a una o varias personas, naturales o jurídicas, la gestión de un servicio cuya prestación sea de su titularidad o competencia, y cuya contrapartida venga constituida bien por el derecho a explotar los servicios objeto del contrato o bien por dicho derecho acompañado del de percibir un precio. En todo caso, el derecho de explotación de los servicios implicará la transferencia al concesionario del riesgo operacional (Lazo Vitoria y Noguera de la Muela, 2018, pp. 189-214).

Respecto de su objeto, hay que señalar que propia ley regula expresamente, en el artículo 284, la posibilidad de que la Administración canalice a través de este tipo de contrato la gestión indirecta de los servicios públicos de su titularidad o competencia. No obstante, igual que sucedía con el antiguo contrato de gestión de servicios públicos, establece una serie de límites: que dichos servicios sean susceptibles de explotación económica por particulares y que no impliquen ejercicio de la autoridad inherente a los poderes públicos.

En realidad, en el caso de que su objeto sea la gestión de un servicio público, no existen apenas diferencias entre el régimen jurídico del antiguo contrato de gestión de servicios públicos y las nuevas concesiones de servicios. Así, se exige que, antes de proceder a la contratación: se establezca el régimen jurídico del servicio público de que se trate, se declare expresamente que la actividad de que se trata queda asumida por la Administración respectiva como propia; se determine el alcance de las prestaciones en favor de los administrados; y se regulen los aspectos de carácter jurídico, económico y administrativo relativos a la prestación del servicio. Del mismo modo, se regulan las prerrogativas de la Administración y las obligaciones del concesionario cuando el objeto del contrato sea la gestión de un servicio público, de manera que, según el artículo 287 de la LCSP de 2017, el concesionario está obligado a organizar y prestar el servicio con estricta sujeción a las características establecidas en el contrato y dentro de los plazos señalados en el mismo, y, en su caso, a la ejecución de las obras conforme al proyecto aprobado por el órgano de contratación y la Administración, por su parte, conservará los poderes de policía necesarios para asegurar la buena marcha de los servicios de que se trate (vid. asimismo, los artículos 291 y ss. de la LCSP de 2017).

De otro lado, el artículo 17 de la LCSP de 2017 define el contrato de servicios como aquel cuyo objeto son prestaciones de hacer consistentes en el desarrollo de una actividad o dirigidas a la obtención de un resultado distinto de una obra o suministro, incluyendo aquellos en que el adjudicatario se obligue a ejecutar el servicio de forma sucesiva y por precio unitario.

Respecto de su objeto, hay que señalar que, también en este caso, en el artículo 312 de la LCSP de 2017, se permite canalizar a través de este tipo de contrato la gestión indirecta de los servicios públicos de su titularidad o competencia, al introducir un régimen especial para aquellos contratos de servicios que conlleven prestaciones directas a favor de la ciudadanía (Menéndez Sebastián, 2020, pp. 375-400).

No obstante, igual que sucedía con el antiguo contrato de gestión de servicios públicos, se establece un límite: que dichos servicios no impliquen ejercicio de la autoridad inherente a los poderes públicos (Almeida Cerreda et al., 2014, p. 540). Nada se dice, sin embargo, sobre la necesidad de que el servicio sea susceptible de explotación por particulares, si bien, parece que este requisito va implícito con la celebración del propio contrato.

Así las cosas, en realidad, en el caso de que el objeto de dichos contratos sea la gestión de un servicio público, las diferencias con el régimen jurídico del antiguo contrato de gestión de servicios públicos son menos evidentes de lo que pudiera parecer y lo mismo sucede respecto del régimen aplicable al contrato de concesión de servicios y al contrato de servicios cuando su objeto sea la gestión de un servicio público. Según el art. 284.2 de la LCSP de 2017, en el caso del contrato de concesión de servicios se exige que, antes de proceder a la contratación: se establezca su régimen jurídico; se declare expresamente que la actividad de que se trata queda asumida por la Administración respectiva como propia de la misma; se determine el alcance de las prestaciones en favor de los administrados, y se regulen los aspectos de carácter jurídico, económico y administrativo relativos a la prestación del servicio.

Del mismo modo que en las concesiones de servicios, en el contrato de servicios se regulan las prerrogativas de la Administración y las obligaciones del contratista cuando el objeto del contrato sea la gestión de un servicio público, de manera que, según el artículo 312 b) LCSP, por una parte, el contratista debe: prestar el 
REALA. Nueva Época - N. ${ }^{16}$, octubre 2021 - ISSN: 1989-8975 - DOI: https://doi.org/10.24965/reala.i16.10965 - [Págs. 98-117]

¿Es posible crear sociedades de economía mixta para la gestión de servicios públicos locales en el marco de contratos de servicios...

Diana Santiago Iglesias

servicio con la continuidad convenida y garantizar a los particulares el derecho a utilizarlo en las condiciones que hayan sido establecidas y mediante el abono en su caso de la contraprestación económica fijada; cuidar del buen orden del servicio; indemnizar los daños que se causen a terceros como consecuencia de las operaciones que requiera el desarrollo del servicio, con la salvedad de aquellos que sean producidos por causas imputables a la Administración; y entregar, en su caso, las obras e instalaciones a que esté obligado con arreglo al contrato en el estado de conservación y funcionamiento adecuados. De otro lado, entre las prerrogativas de la Administración cabe destacar: la inembargabilidad de los bienes afectos al servicio; la potestad de secuestrar o intervenir el servicio si del incumplimiento por parte del contratista se derivase perturbación grave del mismo, no reparable por otros medios, y la Administración no decidiese la resolución del contrato; la atribución a la Administración de los poderes de policía necesarios para asegurar la buena marcha de los servicios.

En consecuencia, a la luz de los expuesto, es el riesgo operacional el criterio básico para decidir el tipo de contrato a celebrar para la gestión indirecta de un servicio público, de manera que, de trasladarse al contratista, procederá la celebración de una concesión de servicios y de no ser así, deberá acudirse al contrato de servicios (Gimeno Feliú, 2018, pp. 4-13; Hernández González, 2018, pp. 477-516; Miguez Macho, 2016, pp. 217-233). No obstante, algunos autores han criticado la configuración legal del riesgo operacional como criterio distintivo entre ambas figuras contractuales, por entender que, en su lugar, la distinción debería buscarse en su diferente objeto, al que sigue un régimen jurídico definido, especialmente, en el caso de los servicios que se prestan a los ciudadanos, motivo por el cual no tendría sentido la categoría de contratos de servicios a los ciudadanos, al tener un régimen jurídico casi coincidente con el de la concesión de servicios públicos (Sahún Pacheco, 2019, p. 191; Laguna de Paz, 2017, p. 68).

\subsection{El encaje de las antiguas modalidades del contrato de gestión de servicios públicos en la LCSP de 2017}

Tras la supresión del contrato de gestión de servicios públicos por la LCSP de 2017, se plantea la incógnita de acerca de la subsistencia de sus diferentes modalidades. En este punto, hay que recordar que, en puridad, ni siquiera podía hablarse bajo la anterior regulación de verdaderas modalidades del contrato. Los criterios de distinción entre ellas no eran uniformes y más que modalidades del contrato de gestión de servicios públicos debía hablarse de modalidades de concesión, es decir, el contrato de gestión de servicios públicos podría haberse denominado, bajo la normativa de contratos anterior, contrato de concesión de servicios públicos, con diferentes subtipos, en función de sus características: en el caso de la gestión interesada, se trataba de una concesión con un régimen de reparto del riesgo determinado; en el caso del concierto, era, de nuevo, una concesión, en la que se introducían limitaciones respecto de los posibles adjudicatarios; en el caso de la sociedad de economía mixta, se condicionaba el contrato a la creación de una sociedad con unos requisitos determinados.

A continuación, se analizará la posible reconducción de las antiguas modalidades de gestión indirecta de servicios públicos a alguno de los tipos contractuales previstos en la nueva LCSP, en concreto, se examinará su encaje en el contrato de concesión de servicios y en el contrato de servicios, según corresponda, en función del mencionado criterio del riesgo operacional (Hernández González, 2016, pp. 53-56).

En primer lugar, por lo que respecta a la gestión interesada, no parece que haya impedimento en encajarla en alguno de los mencionados tipos contractuales. Al fin y al cabo, el elemento que singularizaba a esta forma de gestión frente a las demás era su sistema retributivo, basado en la previsión en los pliegos de cláusulas administrativas particulares de la denominada cláusula de interesamiento, a través de la que se podía establecer un ingreso mínimo en favor de cualquiera de las partes, a abonar por la otra parte, cuando el resultado de la explotación no alcanzase a cubrir un determinado importe de beneficios (Morell Ocaña, 1999, p. 405). De hecho, la doctrina había propuesto durante años su eliminación como modalidad gestora diferenciada y la incorporación de la cláusula de interesamiento que la caracterizaba a los pliegos de condiciones de la concesión (Martín-Retortillo, 1961, pp. 93-98). Por tanto, nada impide que puedan incorporarse dichas cláusulas a los pliegos de alguno de los contratos previstos en la LCSP para la gestión de los servicios públicos, en concreto, a los del contrato de servicios, dado que esta fórmula no implicaría, probablemente, la traslación del riesgo operacional al contratista.

En segundo lugar, las antiguas concesiones -por las que se atribuía a un empresario particular la gestión, a su riesgo y ventura, de un servicio público de su competencia, pudiendo exigirle a cambio el pago de un canon- podrán reconducirse, bien al contrato de servicios, o bien al de concesión de servicios, dependiendo de si se produce o no la traslación del riesgo operacional al contratista-debe recordarse que 
REALA. Nueva Época - N. ${ }^{16}$, octubre 2021 - ISSN: 1989-8975 - DOI: https://doi.org/10.24965/reala.i16.10965 - [Págs. 98-117]

¿Es posible crear sociedades de economía mixta para la gestión de servicios públicos locales en el marco de contratos de servicios..

Diana Santiago Iglesias

el concepto de riesgo y ventura no es equivalente al de riesgo operacional (Sahún Pacheco, 2019, p. 238; Gimeno Feliú, 2018, pp. 4-13; Hernández González, 2018, pp. 477-516; Huergo Lora, 2017, pp. 31-51; Miguez Macho, 2016, pp. 217-233)-.

En cuanto al concierto, su configuración como modalidad del contrato de gestión de servicios públicos había sido objeto de numerosas críticas con anterioridad a la reforma, por exigirse que la contratación de servicios públicos se llevase a cabo con empresarios que viniesen realizando la actividad de que se tratase de forma ordinaria, en lugar de articularse sobre la base de requisitos de solvencia técnica o profesional y, en su caso, de los criterios de adjudicación que se establezcan. En todo caso, los antiguos conciertos entendidos en dicho sentido deberían reconducirse al contrato de servicios o al de concesión de servicios, en función de quién asuma el riesgo operacional. No obstante, teniendo en cuenta las actividades que constituyen su objeto habitualmente (sanidad, servicios sociales, etc...) no parece que exista una exposición real a los riegos de mercado en este tipo de contratos, por lo que, en muchos casos, deberán reconducirse a la figura de los contratos de servicios, si bien no existe una posición pacífica al respecto (Díez Sastre, 2020, pp. 232-262; Garrido Juncal, 2020; Hernández González, 2016, p. 53).

Por último, en cuanto a la sociedad de economía mixta como modalidad del antiguo contrato de gestión de servicios públicos, ésta gozaría de una posición asimilable a la del concesionario en el antiguo contrato de gestión de servicios públicos: «en los contratos de gestión de servicios públicos la sociedad de economía mixta figurará como contratante con la Administración, correspondiéndole los derechos y obligaciones propios del concesionario de servicios públicos» (art. 182 del Real Decreto 1098/2001, de 12 de octubre, por el que se aprueba el Reglamento de la Ley de Contratos de las Administraciones Públicas (en adelante, RLCAP), todavía en vigor, en la medida en que resulte compatible con la LCSP de 2017). Esta remisión genérica del régimen aplicable a la sociedad de economía mixta al régimen del concesionario evidencia la falta de un status de gestor del servicio (Gómez-Ferrer Morant, 2000, p. 1903).

Así, de entrada, podría pensarse que dicha figura tendría encaje en aquellos contratos a los que según la nueva ley pueden reconducirse las antiguas concesiones: concesión de servicios o contrato de servicios, según corresponda, en función del criterio de traslación del riesgo operacional. No obstante, la falta de regulación expresa de las sociedades de economía mixta en el articulado de la LCSP de 2017 y la oscura regulación de las mismas contenida en su disposición adicional vigesimosegunda (en adelante, DA22 de la LCSP de 2017), hacen necesario un análisis más detenido de esta cuestión, el cual se llevará a cabo en el siguiente apartado.

\section{3. ¿PUEDEN EMPLEARSE LAS SOCIEDADES DE ECONOMÍA MIXTA PARA LA GESTIÓN DE SERVICIOS PÚBLICOS TRAS LA LEY 9/2017, 8 DE NOVIEMBRE, DE CONTRATOS DEL SECTOR PÚBLICO?}

Tal y como se ha apuntado, tras la supresión del contrato de gestión de servicios públicos cabe preguntarse si las sociedades de economía mixta continúan siendo una fórmula válida para la gestión de servicios públicos y, de ser así, a través de qué fórmula contractual puede canalizarse la adjudicación a las mismas de su gestión. A continuación, se expondrá el razonamiento deductivo seguido para dar respuesta a dichas cuestiones.

\subsection{Premisas}

\subsubsection{Primera premisa: las sociedades de economía mixta creadas para la gestión contractual de servicios públicos son una fórmula de colaboración público-privada institucionalizada con personalidad jurídico-privada y un régimen jurídico mixto}

De un modo muy simple, partiendo de una interpretación literal de su propia denominación, las sociedades de economía mixta se pueden definir como aquellas entidades mercantiles que cuentan con un capital social de composición en parte pública en parte privada.

En el seno del Ordenamiento de la Unión Europea se han desarrollado una serie de criterios para delimitar el concepto de colaboración público-privada institucionalizada, una de cuyas manifestaciones posibles son las sociedades de economía mixta (Bernal Blay, 2010, pp. 96-105). En este sentido, la Comisión entiende por Colaboración Público-Privada Institucionalizada (en adelante, CPPI) la cooperación entre socios 
REALA. Nueva Época - N. ${ }^{16}$, octubre 2021 - ISSN: 1989-8975 - DOI: https://doi.org/10.24965/reala.i16.10965 - [Págs. 98-117]

¿Es posible crear sociedades de economía mixta para la gestión de servicios públicos locales en el marco de contratos de servicios..

Diana Santiago Iglesias

del sector público y del sector privado que crean una entidad de capital mixto para la ejecución de contratos públicos o concesiones. La aportación privada a los trabajos de la CPPI, además de la contribución al capital u otros activos, consiste en la participación activa en la ejecución de las tareas confiadas a la entidad de capital mixto y/o la gestión de dicha entidad. En cambio, la simple aportación de fondos por un inversor privado a una empresa pública no constituye una $\mathrm{CPPI}^{5}$.

Así, según lo expuesto, para la existencia de una fórmula de colaboración público-privada institucionalizada, por ejemplo, una sociedad de economía mixta, serían necesarios dos elementos: en primer lugar, que haya contribución pública y privada en el capital de la entidad creada y, en segundo lugar, que el socio privado participe, activamente, en la gestión de la entidad y/o en la ejecución del contrato o concesión que tiene encomendada dicha entidad.

Junto a los criterios establecidos en el ámbito comunitario, en el ordenamiento jurídico español se pueden encontrar una serie de preceptos relacionados con la gestión de los servicios públicos, en general, y con la erogación de los servicios públicos locales, en particular, de los cuales se puede inferir una concepción ordinamental de sociedad de economía mixta. Estos preceptos son la disposición adicional vigesimosegunda (en adelante, DA22) de la LCSP de 2017, el artículo 86 de la LBRL, el artículo 104 del Real Decreto Legislativo 781/1986, de 18 de abril, por el que se aprueba el texto refundido de las disposiciones legales vigentes en materia de Régimen Local (en adelante, TRRL) y los artículos 102 y ss. del RSCL.

A partir de dichos preceptos, se podrían definir como aquellas en las que se cumplen cuatro requisitos: primero, su objeto social consiste, o bien en la realización de actividades configuradas, o susceptibles de ser configuradas, como servicios públicos locales; segundo, su capital social se halla compuesto por aportaciones provenientes del sector público y del sector privado; tercero, su actividad consiste, al menos, en la erogación de un servicio público; y cuarto, su gestión y administración se comparte entre el socio privado y el socio público (Santiago Iglesias, 2010, p. 69) ${ }^{6}$.

Este tipo de sociedades tienen un régimen jurídico mixto integrado por normas administrativas y mercantiles, siendo más intensa la aplicación de las primeras en el caso de aquellas cuyo objeto consiste en la gestión de servicios públicos o en la realización de funciones públicas (Santiago Iglesias, 2010, p. 85). La ausencia de una regulación clara de estas entidades en las normas administrativas, que se limitan a remitir la disciplina relativa a la constitución y funcionamiento de la sociedad a las normas mercantiles, hace que sea necesario establecer una serie de principios que permitan conjugar las citadas normas administrativas y mercantiles, y establecer un sistema de prelación en caso de conflicto entre ambos ordenamientos. La doctrina ha propuesto diferentes criterios para resolver dicha situación (Ruiz Ojeda, 1998, p. 113), entre los cuales, cabe citar el siguiente, basado en la posibilidad de excepcionar el régimen general de sociedades derivada de lo dispuesto en el art. 104.2 del TRRL, que permite introducir singularidades en su régimen jurídico por vía estatutaria (Santiago Iglesias, 2017, p. 159). Así las cosas, se propone la aplicación de los siguientes principios, a la luz del art. $103 \mathrm{CE}$, para la resolución de los conflictos que puedan surgir, si bien, no existe una posición doctrinal unánime al respecto: en primer lugar, toda alteración del régimen general de funcionamiento de las sociedades debería tener como fin la protección de un interés general; en segundo lugar, sólo se llevará a cabo la alteración del régimen general de funcionamiento de las sociedades cuando dicho régimen no ofrezca los mecanismos adecuados para la protección del interés general cuya tutela se persigue y, en tercer lugar, las alteraciones del régimen general de funcionamiento de las sociedades introducidas por las normas administrativas han de ser las mínimas indispensables para garantizar la consecución del antedicho interés general y, en consecuencia, proporcionales al mismo.

\subsubsection{Segunda premisa: la selección del socio privado ha de realizarse a través de un procedimiento de concurrencia competitiva}

La garantía de los principios de igualdad de trato, libre competencia y no discriminación por razón de la nacionalidad (art. 43, 49 y 86 del TFUE) y el respeto a la normativa europea de contratación pública hacen

5 Vid. Comunicación interpretativa de la Comisión relativa a la aplicación del Derecho comunitario en materia de contratación pública y concesiones a la colaboración público-privada institucionalizada (CPPI) (2008/C91/02, DOUE de 12 de abril de 2008). Asimismo, vid. el Informe especial del Tribunal de Cuentas Europeo Asociaciones público-privadas en la UE: Deficiencias generalizadas y beneficios limitados, núm. 2/2018.

6 Estos caracteres han sido identificados por el Tribunal Supremo en el FJ4. ${ }^{\circ}$ de su Sentencia de 22 de abril de 2005, Sala de lo Contencioso-Administrativo, Sección cuarta, recurso núm. 7931/2002. 
REALA. Nueva Época - N. ${ }^{16}$, octubre 2021 - ISSN: 1989-8975 - DOI: https://doi.org/10.24965/reala.i16.10965 - [Págs. 98-117]

¿Es posible crear sociedades de economía mixta para la gestión de servicios públicos locales en el marco de contratos de servicios..

Diana Santiago Iglesias

que la selección del socio privado de una sociedad de economía mixta gestora de servicios públicos deba realizarse a través de un procedimiento que garantice la libre concurrencia, no siendo posible la adjudicación directa de la gestión de un servicio público a una sociedad de economía mixta preexistente, la cual colocaría a la empresa que participa en el capital en una situación de ventaja respecto de sus competidores ${ }^{7}$.

Cuando pretende adjudicarse la gestión de un servicio público a una sociedad de economía mixta, pueden darse dos supuestos, fundamentalmente: que la sociedad ya se halle constituida o que se pretenda su creación ex novo. En ambos casos, es necesario celebrar un procedimiento en el que quede garantizada la concurrencia: las entidades adjudicadoras no pueden «recurrir a mecanismos dirigidos a enmascarar la adjudicación de contratos públicos de servicios a empresas de economía mixta», sin embargo, el diseño del mismo será diferente [Comunicación interpretativa de la Comisión relativa a la aplicación del Derecho comunitario en materia de contratación pública y concesiones a la colaboración público-privada institucionalizada (CPPI) (2008/C91/02)].

En el caso de las sociedades de economía mixta preexistentes, la atribución a las mismas de la gestión del servicio de que se trate pasa por su previa participación en el procedimiento de contratación que, en su caso, se celebre y en su eventual selección como contratista ${ }^{8}$. Más problemas se ha planteado respecto de las sociedades de economía mixta de nueva creación, en concreto, respecto del diseño del procedimiento a emplear para la selección del socio privado y para la posterior adjudicación a la nueva sociedad del servicio público de que se trate, cuestión que será objeto de análisis detenido en el siguiente apartado.

\subsubsection{Tercera premisa: en las sociedades de economía mixta creadas ex novo el acto de selección del socio privado va acompañado de la creación de la sociedad de economía mixta y de la atribución a la misma de la gestión del servicio público}

De acuerdo con la interpretación del Ordenamiento jurídico comunitario realizada por la Comisión Europea, deben descartarse como modo adecuado de selección del socio privado aquellos basados en la celebración de una doble licitación -una primera para la selección del socio privado de la CPPI, y una segunda para la adjudicación del contrato público o la concesión a la entidad de capital mixto- por considerarlos poco prácticos -quien haya sido seleccionado como socio, podría terminar siéndolo de una sociedad que no resultase adjudicataria del servicio en cuestión-. Así, se propone el siguiente modo de creación: el socio privado debe ser seleccionado mediante un procedimiento de licitación transparente y competitivo cuyo objeto sea el contrato público o la concesión cuya ejecución corresponderá a la entidad de capital mixto y la contribución operativa del socio privado a la ejecución de esas tareas y/o su contribución administrativa a la gestión de la entidad de capital mixto. En definitiva, lo que la Comisión propone es que la selección del socio privado vaya acompañada de la creación del instrumento de colaboración público-privada institucionalizada y, a su vez, de la adjudicación del contrato público o la concesión a la entidad de capital mixto [Comunicación interpretativa de la Comisión relativa a la aplicación del Derecho comunitario en materia de contratación pública y concesiones a la colaboración público-privada institucionalizada (CPPI) (2008/C91/02)].

Esta fórmula ha sido avalada por la STJUE, de 15 de octubre de 2009, "ACOSET", asunto C-196/08, § 59-63. En este pronunciamiento, el Tribunal rechazó los procedimientos de doble licitación: una para seleccionar al socio privado y otra para adjudicar el servicio a la sociedad de economía mixta ya constituida, justificando dicha posición en los siguientes argumentos: a) un procedimiento así diseñado casa mal con el ahorro de trámites que inspira a las colaboraciones público-privadas institucionalizadas y b) resulta disuasorio tanto para las entidades privadas como las públicas, dada la incertidumbre jurídica que existe respecto de la adjudicación de la concesión al socio privado previamente seleccionado.

7 En principio, aquel negocio jurídico por el que se pretende adjudicar a una sociedad de economía mixta la gestión de un servicio público parece encajar en el concepto de contrato de servicios o de concesión de servicios previstos en el artículo 2.1.9) de la Directiva 2014/24/UE del Parlamento Europeo y del Consejo, de 26 de Febrero de 2014, sobre contratación pública y en el artículo 5.2.b) de la Directiva 2014/23/UE del Parlamento Europeo y del Consejo, de 26 de febrero de 2014, relativa a la adjudicación de contratos de concesión.

Vid., entre otras: STJUE, de 15 de octubre de 2009, "ACOSET", asunto C-196/08, § 56; STJUE de 10 de noviembre de 2005 , "Comisión de las Comunidades Europeas contra República de Austria", asunto C-29/04, § 48 o STJUE, de 11 de enero de 2005 , "Stadt Halle", asunto C-26/03, §52.

8 Al contar con participación de capital privado queda, en cualquier caso, excluida su posible condición de medio propio (Gimeno Feliú, 2019, p. 775). Vid., entre otras, la STJUE, de 11 de enero de 2005, "Stadt Halle", asunto C-26/03 o la STJUE, de 13 de octubre de 2005, "Parking Brixen", asunto C-458/03. 
REALA. Nueva Época - N. ${ }^{16}$, octubre 2021 - ISSN: 1989-8975 - DOI: https://doi.org/10.24965/reala.i16.10965 - [Págs. 98-117]

¿Es posible crear sociedades de economía mixta para la gestión de servicios públicos locales en el marco de contratos de servicios...

Diana Santiago Iglesias

Así, se concluye que puede adjudicarse la gestión del servicio a la sociedad mixta sin necesidad de una doble licitación siempre que la selección del socio privado se realice a través de un procedimiento respetuoso con los principios del derecho comunitario en el que se empleen criterios que no se basen, únicamente, en el capital aportado, sino en los que se tengan en cuenta la capacidad técnica y las características de la oferta respecto de las prestaciones específicas a realizar.

La selección del socio privado siguiendo un procedimiento con dichas características permite, según sostiene el TJUE, la adjudicación directa a la sociedad de economía mixta que eventualmente se cree, siempre y cuando la sociedad conserve el mismo objeto social durante todo el tiempo que dure el contrato y teniendo en cuenta que toda modificación sustancial del mismo obligaría a proceder a una nueva licitación.

Lo cierto es que, en España, la forma en que venía llevándose a cabo la selección del socio privado de las sociedades de economía mixta coincidía, en esencia, con la señalada en la sentencia ACOSET. Las sociedades de economía mixta se configuraban en la normativa de contratos del sector público anterior a 2017, como una modalidad del contrato de gestión de servicios públicos, de manera que la selección del socio privado se llevaba a cabo a través de un único procedimiento, transparente y competitivo, que tenía por finalidad la selección de dicho socio -empleando criterios basados en la capacidad técnica y en las características de las ofertas-. Ésta iba acompañada de la creación de la sociedad de economía mixta y de la atribución a la misma de la gestión del servicio de que se tratase, de manera que dicha sociedad gozaría de una posición asimilable a la del concesionario en la terminología del antiguo contrato de gestión de servicios públicos (art. 182 del RLCAP). El adjudicatario, en primera instancia, era el socio privado, no obstante, el contrato, a través de los pliegos, se condicionaba a la creación posterior de una sociedad de economía mixta a la que correspondería su ejecución (art. 25 del derogado TRLCSP), por lo que, de acuerdo con lo expuesto, de facto ésta asumía una posición asimilable a la del contratista ${ }^{9}$. Así, ni existía en nuestro ordenamiento una doble licitación ni una previsión expresa de la posibilidad de adjudicar directamente a la sociedad resultante la gestión del servicio público de que se tratase -exigencia que, en ningún caso, se deriva del Derecho de la Unión Europea-.

En la actualidad, la supresión del contrato de gestión de servicios públicos, de entrada, no parece que haya afectado al sistema anterior en este punto, siempre que la selección del socio se realice a través de alguno de los procedimientos previstos en la LCSP de 2017 para la celebración del contrato de servicios o de concesión de servicios, fórmulas adecuadas en el nuevo texto legal para canalizar la gestión de un servicio público, quedando así garantizados los principios de igualdad de trato, libre competencia y no discriminación por razón de la nacionalidad ${ }^{10}$. A continuación, se volverá sobre esta cuestión.

\subsubsection{Cuarta: la supresión del contrato de gestión de servicios públicos no impide el recurso a la sociedad de economía mixta como fórmula gestora ni exige la celebración de una doble licitación para la adjudicación del servicio de que se trate}

Como acaba de señalarse, la creación de sociedades de economía mixta para la gestión de servicios públicos en el ordenamiento jurídico español se canalizaba a través del contrato de gestión de servicios públicos, fórmula genuina de nuestro derecho que ha permitido llevar a cabo la selección del socio privado y la adjudicación del servicio a la sociedad de forma totalmente respetuosa con el Derecho de la Unión Europea.

La supresión de dicho contrato a través de la LCSP de 2017 no impide, sin embargo, que se pueda continuar recurriendo a esta figura para la gestión de servicios públicos y, en general, en el marco de cualquier tipo contractual. Como se ha dicho anteriormente, en la actualidad, la gestión de servicios públicos ha de canalizarse a través, bien del contrato de concesión de servicios, bien a través del contrato de servicios, pero nada impide que, en virtud del principio de libertad de pactos (art. 34.1 LCSP de 2017), el contrato de que se trate tenga por objeto la selección del socio privado de la futura sociedad de economía mixta condicionada a la creación posterior de ésta última para llevar a cabo su ejecución, la cual se realizará de acuerdo con

9 Esta concepción, aparentemente sencilla, debe ser matizada, por ejemplo, respecto de la apreciación de las causas de resolución contractual, en concreto, de la contenida en el art. 211 b) de la LCSP de 2017, «la declaración de concurso o la declaración de insolvencia en cualquier otro procedimiento» (Santiago Iglesias, 2015, p. 103), o respecto del disfrute de las garantías del contratista por el socio privado de una sociedad de economía mixta (González-Deleito Domínguez y Carpintero Rodríguez, 2019, p. 5).

10 Sin embargo, aunque España se había mantenido al margen de dicha polémica, en torno a esta situación se han generado múltiples problemas en otros ordenamientos, como el italiano, en el que, finalmente, se ha optado por adoptar la solución postulada por la Comisión. 
REALA. Nueva Época - N. ${ }^{16}$, octubre 2021 - ISSN: 1989-8975 - DOI: https://doi.org/10.24965/reala.i16.10965 - [Págs. 98-117]

¿Es posible crear sociedades de economía mixta para la gestión de servicios públicos locales en el marco de contratos de servicios...

Diana Santiago Iglesias

lo establecido en los pliegos ${ }^{11}$. En ellos se especificarán las características esenciales relativas a la organización y funcionamiento de la nueva sociedad, en especial, de aquellas que se refieren a la composición del capital y a su objeto social, el cual deberá mantenerse inalterado durante la duración del contrato, sin perjuicio de la aplicación del régimen de las modificaciones contractuales contenido en los artículos 203 y ss. de la LCSP de $2017^{12}$.

Es más, como se ha apuntado, ni en la legislación anterior de contratos, ni en la actual, tras la supresión del contrato de gestión de servicios públicos, existe impedimento alguno para crear sociedades de economía mixta en el marco de cualquier tipo contractual, encontrándose, precisamente, en el citado art. 34.1 LCSP de 2017 el amparo legal para hacerlo (equivalente al art. 25 del derogado TRLCSP).

El límite principal a dicho principio en el ámbito del Derecho administrativo se encuentra en la propia ley de contratos, cuyo contenido se presume derecho necesario, primando dicha norma sobre lo establecido en los pliegos en caso de contradicción (Gil Ibáñez, 2020, p. 83). Sin embargo, en el caso que nos ocupa, el principio de libertad de pactos resulta plenamente aplicable puesto que la LCSP no contiene ninguna prohibición expresa respecto de la creación de sociedades de economía mixta en el marco de ninguno de los contratos en ella regulados, salvo las limitaciones derivadas, en la legislación anterior, de la DA29 del TRLCSP y, en la vigente, de la DA22 de la LCSP de 2017, cuyo alcance será analizado a continuación ${ }^{13}$.

Por tanto, con carácter general, y siempre que así se establezca en los pliegos, podrá recurrirse a las sociedades de economía mixta, tanto para la ejecución de contratos que tengan por objeto la gestión de servicios públicos -contrato de servicios o de concesión de servicios- como para la de cualquier otro tipo contractual.

\subsection{Una posible respuesta: las sociedades de economía mixta continúan siendo una fórmula de gestión de servicios públicos tras la LCSP de 2017}

De las premisas anteriormente expuestas parece deducirse que la gestión de un servicio público puede encomendarse a una sociedad de economía mixta previa celebración de un contrato de servicios o de un contrato de concesión de servicios, según corresponda. En ambos casos, el procedimiento de contratación tendrá por objeto la selección del socio privado que participará con la Administración titular del servicio en la sociedad mixta. Así, la adjudicataria del contrato no sería, en primera instancia, la sociedad, aunque, posteriormente, ésta asuma la posición del contratista, ya que el contrato se adjudica al licitador que resulte elegido a condición de que constituya la sociedad de economía mixta en los términos indicados en los pliegos del contrato, acto que irá acompañado de la atribución a la misma de la gestión del servicio público de que se trate.

11 En los contratos del sector público podrán incluirse cualesquiera pactos, cláusulas y condiciones, siempre que no sean contrarios al interés público, al ordenamiento jurídico y a los principios de buena administración. El pliego de condiciones ha venido considerándose por la jurisprudencia como ley de contrato, con fuerza vinculante para las partes. Vid. la STS de 19 de marzo de 2001 , RC 565/1994. En aplicación de la jurisprudencia anterior puede verse, como ejemplo, la Resolución del Tribunal Administrativo Central de Recursos Contractuales de Cantabria núm. 219/2016, de 1 de abril.

12 Respecto a la posibilidad de constituir una sociedad de economía mixta para la gestión de varios servicios públicos, hay que señalar que, desde el punto de vista del Derecho comunitario, no existe ningún impedimento para que existan sociedades plurifuncionales, siempre que se adopten determinadas cautelas. Así, según la Comisión, «el principio de transparencia impone que se indique claramente en la documentación del anuncio de licitación [...] las posibilidades de adjudicación opcional de nuevas tareas. La documentación debería indicar, al menos, el número y las condiciones de aplicación de esas opciones. La información así ofrecida debe ser lo bastante detallada para garantizar una apertura a la competencia equitativa y eficaz» [Vid. Comunicación interpretativa de la Comisión relativa a la aplicación del Derecho comunitario en materia de contratación pública y concesiones a la colaboración público-privada institucionalizada (CPPI) (2008/C91/02)]. Es decir, desde el punto de vista comunitario, lo importante es que en el proceso de selección del socio privado quede claro, de un lado, cuál es el servicio o servicios que se van a erogar por la empresa mixta y, eventualmente, qué otros servicios le pueden ser encomendados y, de otro lado, en qué condiciones se producirán dichas encomiendas. En relación con esta cuestión, la Junta Consultiva de Contratación Administrativa de Galicia en su Informe 1/2009, de 25 de junio, de consulta sobre el régimen jurídico aplicable y ampliación del objeto de los contratos de gestión de servicios públicos, ha señalado que es posible que el objeto del contrato de gestión de servicios públicos recogido en los pliegos esté constituido por prestaciones futuras, es decir, por prestaciones que, eventualmente, podrá llevar a cabo el adjudicatario de dicho contrato, sin que sea necesaria una nueva adjudicación y sin que ello suponga una modificación del contrato ni una vulneración de los principios de concurrencia y transparencia ya que al estar esta circunstancia prevista en los pliegos, los licitadores, en el momento de presentar sus ofertas, tenían conocimiento de la misma. El único requisito que se establece es que, con carácter previo al momento en que se decida llevar a cabo esa nueva actividad, se tramite un expediente contradictorio de aceptación y negociación de las condiciones en el que las partes definan con exactitud las obligaciones y responsabilidades asumidas (Santiago Iglesias, 2010, p. 141).

13 Sobre el principio de libertad de pactos en materia de contratación en el ámbito del Derecho de la Unión Europea, vid. la STJUE, de 19 de junio de 2008, "Nachrichtenagentur GmbH", C-454/06. 
REALA. Nueva Época - N. ${ }^{16}$, octubre 2021 - ISSN: 1989-8975 - DOI: https://doi.org/10.24965/reala.i16.10965 - [Págs. 98-117]

¿Es posible crear sociedades de economía mixta para la gestión de servicios públicos locales en el marco de contratos de servicios..

Diana Santiago Iglesias

Así las cosas, la cuestión ahora reside en encajar dicha conclusión con el contenido de la DA22 de la LCSP de 2017, «adjudicación de contratos de concesión de obras y de concesión de servicios a sociedades de economía mixta», en la que algunos autores han visto un obstáculo al empleo de las sociedades de economía mixta para la gestión de servicios públicos en el marco de contratos de servicios (Alemany Garcías, 2019, p. 124; Fuentes i Gasó, 2019, p. 43; Rego Blanco, 2017a, p. 66; Rego Blanco, 2017b, p. 151), cuestión que será objeto de análisis en el siguiente apartado.

\section{LÍMITES AL EMPLEO DE LAS SOCIEDADES DE ECONOMÍA MIXTA PARA LA GESTIÓN DE SERVICIOS PÚBLICOS}

\subsection{Límites derivados de la disposición adicional vigesimosegunda de la LCSP de 2017}

\subsubsection{Origen de la disposición adicional vigesimosegunda de la LCSP de 2017}

El origen de la DA 22 de la LCSP de 2017 se encuentra en la disposición adicional trigésimo-quinta de la Ley 30/2007, de 30 de octubre, de Contratos del Sector Público, introducida por la disposición final 16.34 de la Ley 2/2011, de 4 de marzo, de Economía Sostenible, que dio lugar a la disposición adicional vigésimo novena del Real Decreto Legislativo 3/2011, de 14 de noviembre, por el que se aprueba el texto refundido de la Ley de Contratos del Sector Público.

No obstante, el contenido de sus antecesoras se aleja bastante del actual. En la DA35 de la LCSP de 2007 se establecía que los contratos públicos y concesiones podían adjudicarse directamente a una sociedad de economía mixta en la que concurriese capital público y privado, siempre que la selección del socio privado se hubiese efectuado de conformidad con las normas establecidas en la LCSP de 2007 para la adjudicación del contrato cuya ejecución constituyese su objeto y siempre que no se introdujesen modificaciones en el objeto y las condiciones del contrato que se hubiesen tenido en cuenta en la selección del socio privado.

Lo cierto es que, en su redacción original, dicha disposición se limitaba a reiterar la posibilidad de hacer lo que ya era una realidad aplicando el clausulado general de la ley de contratos que, de un lado, configuraba expresamente la sociedad de economía mixta como una forma del contrato de gestión de servicios públicos $y$, de otro lado, en virtud de la libertad de pactos, permitía el recurso a esta figura en el marco de otros tipos contractuales. A pesar de la innecesaridad de su contenido material -el cual se derivaba del Derecho de la Unión Europea y de lo dispuesto en la normativa interna de contratos públicos- lo cierto es que no puede negarse el valor didáctico de dicha disposición, en la que se regulaban de forma expresa, por primera vez en nuestro ordenamiento, ciertos límites respecto de estas fórmulas de $\mathrm{CPPI}$, en concreto, en lo que se refiere a la modificación del objeto y de las condiciones del contrato que, en su caso, se hubiese celebrado. Es decir, se condicionaba expresamente la realización por la sociedad de otras actividades distintas de aquella que constituía el objeto de contrato en el marco del cual se creaba y, en su caso, se introducían límites respecto de su actividad extra moenia (Santiago Iglesias, 2010, p. 141) ${ }^{14}$.

La disposición adicional vigésimo novena del Real Decreto Legislativo 3/2011, de 14 de noviembre, por el que se aprueba el texto refundido de la Ley de Contratos del Sector Público (en adelante, TRLCSP), mantuvo la redacción anterior y añadió un segundo párrafo relativo a las formas de financiación a las que podían acudir estas sociedades: ampliaciones de capital -siempre que no se modificasen las condiciones esenciales de adjudicación, salvo que se hubiese previsto en el contrato- y titulización de derechos de cobro.

En la vigente LCSP de 2017, el equivalente a dicho precepto se encuentra en la DA22, cuya nueva redacción ha dado lugar a dudas interpretativas acerca de su alcance, que serán objeto de análisis en el siguiente apartado.

\subsubsection{Alcance de la disposición adicional vigesimosegunda de la LCSP de 2017}

La DA22 de la LCSP de 2017 ha introducido algunos cambios relevantes respecto de sus homólogas, anteriormente referidas.

14 Vid. Comunicación interpretativa de la Comisión relativa a la aplicación del Derecho comunitario en materia de contratación pública y concesiones a la colaboración público-privada institucionalizada (CPPI) (2008/C91/02). 
REALA. Nueva Época - N. ${ }^{16}$, octubre 2021 - ISSN: 1989-8975 - DOI: https://doi.org/10.24965/reala.i16.10965 - [Págs. 98-117]

¿Es posible crear sociedades de economía mixta para la gestión de servicios públicos locales en el marco de contratos de servicios...

Diana Santiago Iglesias

En su primer párrafo, se disciplina la posibilidad de adjudicar directamente a las sociedades de economía mixta los contratos de concesión de obras y de concesión de servicios siempre y cuando se cumplan, fundamentalmente, dos condiciones: mayoría del capital público en dicha sociedad y elección del socio privado a través de los procedimientos de adjudicación disciplinados en la LCSP para dichos tipos de contrato.

Asimismo, se recuerda que la modificación de los contratos de concesión de obras o de concesión de servicios de que se trate únicamente se podrá realizar de conformidad con el régimen contenido en la Subsección $4 .^{a}$ de la Sección $3 .^{a}$ del Capítulo I del Título I del Libro Segundo

En su segundo párrafo, se introduce expresamente la prohibición de que la sociedad de economía mixta acceda como concesionaria a otros contratos diferentes de los de concesión de obras o concesión de servicios que, en su caso, se hubiesen celebrado, recordando la necesidad de que, para ello, se celebre un nuevo procedimiento de licitación.

No obstante, lo cierto es que, sin perjuicio del valor didáctico de estas dos últimas precisiones, su contenido se derivaba ya del Derecho de la Unión Europea y del articulado de la propia LCSP de 2017, dado que, de un lado, el régimen de modificados contractuales resultaría de aplicación, en todo caso, con independencia de incluir esta previsión expresa (Rego Blanco, 2017b, p. 158) y, de otro lado, la prohibición de adjudicación de nuevos contratos sin licitación previa es consustancial a la normativa contractual ${ }^{15}$.

\subsubsection{1. Ámbito de aplicación: ¿contiene la DA 22 de la LCSP de 2017 el régimen jurídico general aplicable a este tipo de sociedades o sólo una excepción al mismo para aquellas constituidas en el marco de un contrato de concesión de servicios o de concesión de obras?}

La redacción de la DA22 es poco clara y, de su literalidad es posible extraer, al menos, dos posibles lecturas.

El análisis exegético de dicho precepto no es suficiente para determinar el alcance de su contenido. Por este motivo, se ha acudido al método teleológico, empleado de dos formas: de un lado, se ha confrontado el resultado del análisis literal de la DA22 con el resto de la LCSP, con el objetivo de garantizar que éste respete su lógica interna y la lógica del Ordenamiento en el que se integra y, de otro lado, se ha confrontado la lectura literal de la DA22 con los fines perseguidos por la LCSP de 2017.

En la nueva LCSP son escasas las referencias expresas a las sociedades de economía mixta, limitadas, básicamente, al art. 28.3 de la LCSP de 2017 -donde se contiene una mención a las mismas respecto de la justificación de la necesidad e idoneidad del contrato y la eficiencia en la contratación- y a la mencionada DA 22 de la LCSP de 2017, sobre la adjudicación de contratos de concesión de obras y de concesión de servicios a sociedades de economía mixta.

Así, en virtud del principio de libertad de pactos (art. 34.1 de la LCSP de 2017) y en ausencia de prohibición alguna de recurrir a este tipo de sociedades al disciplinar el régimen aplicable a los contratos de servicios y de concesión de servicios -tipos contractuales apropiados en la nueva ley para la gestión de servicios públicos-, nada impediría que se introdujese como condición contractual la creación de una sociedad de economía mixta participada por la Administración que licita el contrato y por el socio privado que resultase seleccionado para su ejecución en los términos indicados en los pliegos. Esta lectura sería, asimismo, compatible con lo dispuesto en el art. 28.3 de la LCSP de 2017: «De acuerdo con los principios de necesidad, idoneidad y eficiencia establecidos en este artículo, las entidades del sector público podrán, previo cumplimiento de los requisitos legalmente establecidos, celebrar contratos derivados de proyectos promovidos por la iniciativa privada, en particular con respecto a los contratos de concesión de obras y concesión de servicios, incluidos en su modalidad de sociedad de economía mixta». Este artículo, se limita a recordar la posibilidad de que las entidades públicas colaboren con entidades privadas, previendo, a título ejemplificativo, la posibilidad de que se acuda, para ello, a sociedades de economía mixta en el marco de contratos de concesión de obra y concesión de servicio, pero sin impedir, en modo alguno, que puedan constituirse en el seno de otros contratos.

Siguiendo la argumentación anterior, cabría concluir que es posible crear sociedades de economía mixta para la ejecución de cualquier contrato administrativo. No obstante, esta regla general debería completarse con lo dispuesto en la DA22 de la LCSP de 2017, que introduciría ciertos límites a su empleo como

15 En este sentido, debe recordarse una vez más, que las sociedades de economía mixta no tienen la condición de medio propio, al contar con participación privada en su capital y, por tanto, no caben, respecto de ellas, los encargos sin una licitación previa. 
REALA. Nueva Época - N. ${ }^{16}$, octubre 2021 - ISSN: 1989-8975 - DOI: https://doi.org/10.24965/reala.i16.10965 - [Págs. 98-117]

¿Es posible crear sociedades de economía mixta para la gestión de servicios públicos locales en el marco de contratos de servicios...

Diana Santiago Iglesias

instrumento para canalizar contratos de concesión de servicios y de concesión de obras, los cuales deberían ser objeto, en todo caso, de interpretación restrictiva: odiosa sunt restringenda. A continuación, se examinará su posible alcance.

Teniendo en cuenta su ubicación, entre las disposiciones adicionales de la LCSP de 2017, podría pensarse que la DA22 establece particularidades respecto del uso de las sociedades de economía mixta en el marco, únicamente, de los contratos de concesión de servicios y de concesión de obras, es decir, contendría una excepción a la regla general antes expuesta. Así parece desprenderse, además, de una interpretación literal de su propio título: "Adjudicación de contratos de concesión de obras y de concesión de servicios a sociedades de economía mixta".

La incorporación de este régimen especial en una disposición adicional, aunque introduce cierta confusión, podría estar justificada por la finalidad de dicho tipo de disposiciones: incorporar las reglas que no puedan situarse en el articulado sin perjudicar su coherencia y unidad interna ${ }^{16}$. Así, ante la ausencia de un régimen general aplicable a las sociedades mixtas en el articulado -el cual hubiese sido deseable-, la regla es la posibilidad de introducir como condición, en cualquier contrato, la creación de una sociedad de economía mixta, con las modulaciones contenidas en la DA22, las cuales se aplicarían, únicamente, en el caso de los contratos de concesión de servicios y de concesión de obras. La peculiaridad introducida por la DA22 para estos casos se reduce, esencialmente, a la exigencia de que la sociedad de economía mixta que se cree sea mayoritariamente pública, dado que el resto de su contenido resultaría de aplicación a toda sociedad mixta constituida en el seno de cualquier otro contrato regulado en la LCSP de 2017, tal y como se ha apuntado más arriba, por tratarse de límites derivados del propio articulado de la LCSP y no, exclusivamente, de la DA22 de la LCSP de 2017.

En todo caso, la opción del legislador de establecer esta exigencia resulta cuestionable, tanto formal como materialmente. Desde el punto de vista formal, lo más conveniente habría sido introducir una regulación más completa del régimen jurídico-contractual de las sociedades de economía mixta en el articulado de la ley y, desde el punto de vista material, no se entiende la necesidad de limitar la participación privada en el capital social de este tipo de sociedades, teniendo en cuenta que su objeto consiste en ejecutar contratos de concesión de obras y de concesión de servicios, caracterizados por trasladar el riesgo operacional al contratista, cuya posición ocupa, en este caso, una sociedad, curiosamente, con mayoría de capital público. Con independencia de su posición sobre el alcance de la DA22 de la LCSP de 2017, la doctrina coincide en criticar esta exigencia (Gimeno Feliú, 2019, p. 775; Rego Blanco, 2017b, p. 157).

En esta línea parece situarse el Tribunal Constitucional, quien, al analizar la posible vulneración por la regulación de la DA22 LCSP de 2017 del principio de autoorganización alegada por el Gobierno de Aragón, ha señalado que: «el objeto de la disposición adicional impugnada no es la creación de sociedades de economía mixta, sino la adjudicación de concesiones de obras o de servicios a las ya existentes o de las que se constituyan a tales efectos. [...]». (STC 68/2021, de 18 de marzo de 2021, FJ 7Bj). Podría deducirse de ella que la DA22 no resulta de aplicación a toda sociedad de economía mixta sino sólo a la adjudicación de contratos de concesión de obras o de concesión de servicios a aquellas que, o bien ya han sido creadas, o bien serán creadas a estos efectos. Si bien, no se ha profundizado en dicha sentencia en la cuestión planteada en este trabajo.

Frente a ésta que acaba de exponerse, caben otras posibles lecturas de la DA22, según las cuales dicho precepto contendría la definición legal de sociedad de economía mixta a efectos de la normativa de contratación pública, de tal manera que sólo podrían constituirse sociedades de economía mixta en los supuestos expresamente regulados en la DA 22, es decir, en el marco de contratos de concesión de servicios y de concesión de obras y siempre y cuando la participación social sea mayoritariamente pública y se seleccione al socio privado a través de los procedimientos previstos en la ley. Se trata ésta de una lectura de la norma que va más allá de las exigencias de las Directivas en materia de contratos públicos; no obstante, ha encontrado respaldo entre la doctrina académica (Alemany Garcías, 2019, p. 124; Fuentes i Gasó, 2019, pp. 37-43; Rego Blanco, 2017b, p. 151) y ha sido asumida por algunas Juntas Consultivas de Contratación ${ }^{17}$.

16 De acuerdo con la Resolución de 28 de julio de 2005, de la Subsecretaría, por la que se da publicidad al Acuerdo del Consejo de Ministros, de 22 de julio de 2005, por el que se aprueban las Directrices de técnica normativa (la2), en la redacción del contenido de la parte dispositiva de una norma ha de seguirse el siguiente orden: a) de lo general a lo particular; b) de lo abstracto a lo concreto; c) de lo normal a lo excepcional; d) de lo sustantivo a lo procesal).

17 Vid., por ejemplo, el Informe de la Junta Consultiva de Contratación Pública del Estado, expediente 120/18, p. 7. No obstante, en dicho informe se puntualiza que aquellos contratos celebrados con anterioridad a la entrada en vigor de la LCSP de 2017 se rigen, 
REALA. Nueva Época - N. ${ }^{16}$, octubre 2021 - ISSN: 1989-8975 - DOI: https://doi.org/10.24965/reala.i16.10965 - [Págs. 98-117]

¿Es posible crear sociedades de economía mixta para la gestión de servicios públicos locales en el marco de contratos de servicios..

Esta segunda opción interpretativa se construye sobre los siguientes pilares: la jurisprudencia contenida en la mencionada STJUE "ACOSET" -la cual, como se ha señalado, no sería, en realidad, un obstáculo a la primera opción interpretativa que se ha apuntado- y la lectura comparada de la nueva LCSP con el derogado TRLCSP. En este último, se contemplaba la sociedad de economía mixta como una de las modalidades de contrato de gestión de servicios públicos (art. 211 TRLCSP), introduciendo a través de la DA 29 el régimen jurídico general aplicable a las sociedades de economía creadas no sólo en el marco de dicho contrato sino en el de cualquier contrato público. Así, quienes defienden esta opción interpretativa parecen sostener que la creación de cualquier sociedad de economía mixta requiere de una previsión normativa expresa, la cual se encontraría en la DA22 de la LCSP de 2017. Así, de acuerdo con esta lectura, mientras la derogada DA29 amparaba la creación de sociedades de economía mixta en el marco de cualquier contrato, la vigente DA22 LCSP habría limitado dicha figura a la ejecución de concesiones de obra y concesiones de servicio.

No obstante, la equiparación del sentido de ambas adicionales no parece que pueda realizarse de forma automática.

Tal y como se ha explicado en el apartado relativo al origen de la DA 22 LCSP, la derogada DA29 no podía entenderse como una habilitación normativa para la constitución de sociedades de economía mixta en el marco de un contrato administrativo. El valor de la DA29 era fundamentalmente didáctico, dado que la habilitación normativa para la creación de estas sociedades ya existía, en virtud, del mencionado principio de libertad de pactos, de acuerdo con el cual la adjudicación de cualquier contrato podía condicionarse en los pliegos a la creación posterior de una sociedad de economía mixta con las características que en ellos se hubiesen fijado. No se encontraba dicha habilitación normativa el antiguo contrato de gestión de servicios públicos en su modalidad de sociedad de economía mixta, ya que, en realidad, su adjudicatario era el socio privado y no la sociedad en sí misma, de modo que la atribución de la gestión del servicio a la sociedad mixta no se producía automáticamente en un primer momento sino, tras la selección del socio, en aplicación de las condiciones contenidas en los pliegos del contrato, donde se preveía la de crear con posterioridad una sociedad con las características establecidas en ellos. En puridad, esta modalidad del contrato de gestión de servicios públicos no era más que un tipo de concesión condicionada, en virtud de los pliegos del contrato, a la creación de una sociedad con unos requisitos determinados. Así, por lo expuesto, cabe concluir que la supresión de dicho contrato administrativo no ha afectado, en absoluto, a la posibilidad de continuar empleando este tipo de sociedades para la gestión de servicios públicos.

\subsubsection{2. ¿Introduce alguna novedad la DA22 LCSP respecto de las entidades que pueden tener} la condición de socio público en las sociedades de economía mixta gestoras de servicios públicos?

Las sociedades de economía mixta gestoras de servicios públicos locales pueden definirse como aquellas en las que se cumplen cuatro requisitos: primero, su objeto social consiste en la realización de actividades configuradas, o susceptibles de ser configuradas, como servicios públicos locales; segundo, su capital social debe estar compuesto por aportaciones provenientes del sector público y del sector privado; tercero, su actividad debe consistir, al menos, en la erogación de un servicio público, y cuarto, su gestión y administración debe compartirse entre el socio privado y el socio público (Santiago Iglesias, 2010, p. 69).

Respecto, en concreto, de la composición de su capital social, de forma idéntica, el antiguo artículo 156 del TRLCAP y el derogado artículo 253.d) de la LCSP de 2007 (equivalente al art. 277 TRLCSP de 2011), al regular las distintas modalidades del contrato de gestión de servicios públicos, señalaban como posibles socios públicos a la propia Administración titular del servicio o a una entidad pública de ella dependiente: «la Administración participe, por sí o por medio de una entidad pública, en concurrencia con personas naturales o jurídicas».

La vigente LCSP de 2017, como se ha indicado, no contiene una definición legal, ni siquiera mínima, como sucedía en sus predecesoras, de sociedad de economía mixta, eliminándose, por tanto, la referencia expresa a la posibilidad de que la Administración titular del servicio de que se trate pueda participar en dicho tipo de sociedades, además de por sí misma, a través de alguna de sus entidades dependientes.

en virtud de los dispuesto en la Disposición transitoria primera, apartado segundo, por la normativa anterior, de modo que a las sociedades de economía mixta creadas en el marco de dichos contratos no les resultarían de aplicación dichos límites, en el caso que se les adjudicase directamente la ejecución de nuevas prestaciones previstas en el contrato inicial. Asimismo, vid. el Informe $22 / 2018$, de 25 de septiembre, de la Junta Consultiva de Contratación Administrativa de la Comunidad Autónoma de Aragón, p. 11. 
REALA. Nueva Época - N. ${ }^{16}$, octubre 2021 - ISSN: 1989-8975 - DOI: https://doi.org/10.24965/reala.i16.10965 - [Págs. 98-117]

¿Es posible crear sociedades de economía mixta para la gestión de servicios públicos locales en el marco de contratos de servicios...

Diana Santiago Iglesias

Por su parte, la DA 22 de la LCSP de 2017 no introduce especialidad alguna respecto de la naturaleza de las entidades que pueden ostentar la condición de socio público en dicho tipo de sociedades, limitándose a exigir para el caso de aquellas creadas en el marco de contratos de concesión de obras y de concesión de servicios, como es lógico, la concurrencia de capital público -si bien, mayoritario- y privado ${ }^{18}$.

Para responder a esta cuestión, hay que diferenciar dos supuestos: de un lado, la entidad que licita el contrato y, de otro, la entidad a través de la cual podría ésta actuar como socio público en la sociedad de economía mixta, dado que ambas no tienen por qué coincidir, necesariamente.

Respecto de las entidades que pueden celebrar un contrato de servicios o de concesión de servicios a ejecutar a través de una sociedad de economía mixta, de un lado, se encontrarían aquellas consideradas como administración pública a efectos de la LCSP, que celebrarían, en puridad, contratos administrativos típicos de servicios o concesión de servicios y, de otro lado, entidades calificadas como poderes adjudicadores no administración pública que celebrarían contratos privados con un contenido análogo al de los contratos mencionados ${ }^{19}$. Nada obsta, de entrada, a que en el marco de cualquier contrato con dicho objeto celebrado por un poder adjudicador no administración pública se introdujese en sus pliegos la condición de crear una sociedad mixta.

Por lo que se refiere a las entidades que, eventualmente, podrían ostentar la condición de socio público en este tipo de sociedades, desaparecida la limitación contenida en la regulación anterior que exigía que se tratase de entidades con personalidad jurídico pública, no parece que exista inconveniente en que la entidad licitadora pueda participar a través de alguna de sus entidades instrumentales, con independencia de su personalidad jurídica, pública o privada, tanto respecto de los supuestos comprendidos en el ámbito de la DA22 de la LCSP de 2017 (contratos de concesión de obras y contratos de concesión de servicios) como respecto de cualquier otro contrato regulado en la ley cuya ejecución se lleve a cabo a través de una sociedad mixta ${ }^{20}$. No obstante, aún no siendo necesario, esta posibilidad debería preverse en los pliegos.

Analizada la cuestión, en general, respecto de los socios públicos de sociedades de economía mixta constituidas en el marco de contratos servicios y de concesión de servicios, a continuación, se examinará quién puede ostentar la posición de socio público en el caso sociedades creadas en el marco de dichos contratos cuando su objeto sea la gestión de un servicio público local.

De un lado, por lo que se refiere a la entidad licitadora del contrato de servicios o de concesión de servicios, al tener por objeto la gestión de un servicio público, parece que la celebración del contrato deberá corresponder únicamente a la Administración titular del servicio, dadas las funciones que deberá asumir: establecer su régimen jurídico, declarar expresamente que asume como propia la actividad de que se trata, determinar el alcance de las prestaciones en favor de los administrados, y regular los aspectos de carácter jurídico, económico y administrativo relativos a la prestación del servicio (art. 284.2 LCSP y 312 a LCSP). Así las cosas, el contrato deberá celebrarlo una entidad con la consideración de administración pública a efectos de la LCSP y se calificará como administrativo.

De otro lado, respecto de las entidades que, además de la propia administración titular del servicio, puedan ser empleadas por ésta para participar como socio público en una sociedad mixta en el ámbito local, no parece que exista inconveniente, con carácter general, en que pueda otorgarse la condición de socio público en dicha sociedad a una entidad de ella dependiente, al margen de su personalidad jurídico-pública o privada, al haberse eliminado del texto de la LCSP de 2017 la exigencia de que cuente con personalidad jurídico pública. De acuerdo con el art. 85 LBRL, podrían ostentar tal condición los organismos autónomos, las entidades públicas empresariales y las sociedades mercantiles íntegramente públicas.

18 Algunos autores han apuntado la posibilidad, a partir del análisis de la DA22 de la LCSP, de que puedan actuar como socios públicos de una sociedad de economía mixta otras entidades del sector público que no tengan la consideración de Administración pública (Fuentes I Gasó, 2019, p. 41; Rego Blanco, 2017b, p. 155).

$19 \mathrm{El}$ art. 15.1 de la LCSP define los contratos de concesión de servicios como aquellos en cuya virtud uno o varios poderes adjudicadores encomiendan a título oneroso a una o varias personas, naturales o jurídicas, la gestión de un servicio cuya prestación sea de su titularidad o competencia, y cuya contrapartida venga constituida bien por el derecho a explotar los servicios objeto del contrato o bien por dicho derecho acompañado del de percibir un precio. No obstante, en puridad, el régimen jurídico del contrato será diferente en función de que la parte contratante tenga la condición de administración pública o de poder adjudicador no administración pública.

20 Un posible límite podría ser, por ejemplo, que las entidades dependientes tuviesen la condición de medio propio respecto de la Administración matriz, con el fin de proteger el principio de libre concurrencia. 
REALA. Nueva Época - N. ${ }^{16}$, octubre 2021 - ISSN: 1989-8975 - DOI: https://doi.org/10.24965/reala.i16.10965 - [Págs. 98-117]

¿Es posible crear sociedades de economía mixta para la gestión de servicios públicos locales en el marco de contratos de servicios..

Diana Santiago Iglesias

No obstante, cuando la participación en la sociedad se realice a través de alguna de estas entidades, habrán de tenerse en cuenta los límites establecidos en la disposición adicional novena de la LBRL, a los que se hará referencia en apartados posteriores.

\subsubsection{3. ¿Cómo se conjuga el contenido de la DA22 LCSP y del art. 69 del Real Decreto-ley 36/2020, de 30 de diciembre, por el que se aprueban medidas urgentes para la modernización de la Administración Pública y para la ejecución del Plan de Recuperación, Transformación y Resiliencia?}

El art. 69 del Real Decreto-ley 36/2020, de 30 de diciembre, por el que se aprueban medidas urgentes para la modernización de la Administración Pública y para la ejecución del Plan de Recuperación, Transformación y Resiliencia (en adelante RDPRTR) contiene el régimen aplicable en aquellos casos en que la ejecución del Plan de Recuperación, Transformación y Resiliencia de la Economía Española (en adelante, PRTR) se lleve a cabo a través de sociedades de economía mixta.

En concreto, su regulación se circunscribe a aquellos supuestos en que se emplee este tipo de sociedades en el marco de contratos de concesión de obras o de concesión de servicios.

Su redacción, sigue, esencialmente, el mismo esquema de la DA22 de la LCSP de 2017, refiriéndose, de forma equívoca, como se ha señalado, a la adjudicación directa de dichos contratos a este tipo de sociedades. No obstante, en este precepto, se distinguen dos supuestos: a) aquellos referidos a la ejecución de un contrato de concesión de obras o de concesión de servicios, cuando esté sujeto a regulación armonizada en el sentido definido por la Ley 9/2017, de 8 de noviembre o sujeto al Real Decreto-ley 3/2020, de 4 de febrero, relativo a un proyecto enmarcado en el Plan de Recuperación, Transformación y Resiliencia de la Economía Española y b) aquellos otros no sujetos a regulación armonizada en el sentido anterior, pero que conforme a la disposición adicional octava de la Ley 9/2017, de 8 de noviembre, deban sujetarse a esta última Ley por no superar los umbrales correspondientes, cuando dicho contrato tenga por objeto el desarrollo de un proyecto enmarcado en el PRTR.

En ambos casos, al igual que sucede en la DA22, se exige que en la sociedad de que se trate concurra mayoritariamente capital público con capital privado y, con una finalidad esencialmente didáctica, se dispone, de un lado, que la selección del socio privado se haya realizado de conformidad con los procedimientos establecidos en la normativa de contratos públicos y, de otro lado, que cualquier alteración de los términos iniciales del contrato se sujete al régimen de modificación contractual previsto en la misma.

Una peculiaridad importante respecto del régimen contenido en la DA22 LCSP es la distinción, dentro del supuesto relativo a los contratos no sujetos a regulación armonizada, de diferentes regímenes en función de la naturaleza del sujeto que actúe como socio público en la sociedad mixta de que se trate. Así, se diferencia entre aquellos casos en que la selección del socio privado se lleve a cabo por una entidad del sector público que no tenga la consideración de administración pública a efectos de la LCSP -respecto de los cuales se remite a las reglas del art. 312.2 b) LCSP y a las especialidades reguladas en el propio art. 69.3 del RDPRTR-y aquellos otros en los que la selección del socio privado se lleve a cabo por una administración pública -en los que se aplicarán los procedimientos de la LCSP-.

Del mismo modo que se ha indicado al analizar la DA22 LCSP y con valor fundamentalmente didáctico, el art. 69 RDPRTR contiene, además: una remisión a la LCSP respecto del régimen aplicable a la modificación de los contratos de concesión de obras y concesión de servicios que se adjudiquen directamente con arreglo a lo previsto en dicho precepto; la advertencia de que la adjudicación a la sociedad de economía mixta que eventualmente se cree requiere de la celebración de un nuevo procedimiento de licitación y, por último, la referencia a los posibles medios de financiación a utilizar.

En consecuencia, el art. 69 RDPRTR reproduce, en esencia, el contenido de la DA22, introduciendo algunas novedades. En especial, hay que llamar la atención sobre la diferenciación que realiza entre el régimen aplicable a contratos celebrados por administraciones públicas y por otros entes del sector público que, no obstante, tendrán la consideración de contratos privados, sujetos a un régimen jurídico sustancialmente diferente. Asimismo, resulta llamativo el hecho de que se omite en su articulado el régimen aplicable a los contratos celebrados por poderes adjudicadores no administración pública.

Así las cosas, siguiendo el razonamiento expuesto en los apartados precedentes, en resumen, el régimen general sería la posibilidad de constituir sociedades de economía mixta en el marco de cualquier contrato celebrado por entidades sujetas a la LCSP, con las especialidades introducidas, de un lado, en la DA22, respecto de los contratos de concesión de obra y concesión de servicios y, de otro lado, en el art. 69 del RDPRTR respecto de dichos contratos, cuando los liciten administraciones públicas u otras entidades 
REALA. Nueva Época - N. ${ }^{16}$, octubre 2021 - ISSN: 1989-8975 - DOI: https://doi.org/10.24965/reala.i16.10965 - [Págs. 98-117]

¿Es posible crear sociedades de economía mixta para la gestión de servicios públicos locales en el marco de contratos de servicios..

Diana Santiago Iglesias

sujetas a la normativa de contratos públicos, siempre que se celebren en el marco proyectos del Plan de Recuperación, Transformación y Resiliencia de la Economía Española. EI RDPRTR es, en realidad, una norma especial en la que se prevén mecanismos ágiles para la ejecución eficaz de los fondos vinculados al Plan europeo de Recuperación, estableciendo normas específicas para la contratación vinculada a estos fondos (Díez Sastre, 2021, p. 7; Gimeno Feliú, 2021).

\subsection{Límites derivados de la modificación de la LBRL introducida por la Ley $27 / 2013$, de 27 de diciembre, de Racionalización y Sostenibilidad de la Administración Local}

En el ámbito local, se aprovechó el proceso de reforma de la normativa básica local, que cristalizó con la aprobación de la LRSAL, para adoptar una serie de medidas tendentes, por una parte, a reducir el tamaño de su sector público, mediante la extinción de aquellas sociedades en las que se dieran determinadas circunstancias y, por otra parte, a reordenar su crecimiento futuro, introduciendo importantes limitaciones al recurso a estas fórmulas (Boto Álvarez, 2014, pp. 504-515; Martínez-Alonso Camps, 2014, p. 620; Montoya Martín, 2014, pp. 34-41). A continuación, por su relación directa con el tema que aquí se estudia, se analizarán aquellas medidas previstas en la nueva Disposición Adicional Novena LBRL, cuya redacción ha sido introducida por la LRSAL, de las que, eventualmente, podrían derivarse límites a la creación de nuevas sociedades de economía mixta (Santiago Iglesias, 2017, p. 161).

Tras la entrada en vigor de dicha reforma, con carácter previo a la creación de una sociedad mercantil en el ámbito local, es necesario analizar, en cada caso, si se cumplen los presupuestos exigidos para ello que se expondrán a continuación.

En primer lugar, se encuentran aquellas medidas mediante las que se prohíbe la creación de holdings. Así, en el apartado tercero de la nueva Disposición Adicional Novena LBRL, se prohíbe a los organismos, entidades, sociedades, consorcios, fundaciones, unidades y demás entes que estén adscritos, vinculados en dependencia, a efectos del Sistema Europeo de Cuentas, de cualquiera de las entidades locales del citado art. 3.1 LBRL o de sus organismos autónomos: a) constituir; b) participar en la constitución; c) adquirir nuevos entes de cualquier tipología, independientemente de su clasificación sectorial en términos de contabilidad nacional. Así, de acuerdo con esta previsión, en el ámbito local no parece posible que las entidades dependientes de las entidades locales del art. 3.1 LBRL (municipio, provincia e isla) participen como socio público en una sociedad de economía mixta gestora de servicios públicos.

En segundo lugar, las entidades locales señaladas en el art. 3.1 LBRL y los organismos autónomos de ellas dependientes, según lo dispuesto en el párrafo primero de la Disposición Adicional Novena LBRL, no podrán adquirir, constituir o participar en la constitución, de forma directa o indirecta, de nuevos organismos, entidades, sociedades, consorcios, fundaciones, unidades y demás entes, durante el tiempo de vigencia de su plan económico financiero o de su plan de ajuste. Asimismo, a estas entidades no se les permite realizar aportaciones patrimoniales ni suscribir ampliaciones de capital de sociedades mercantiles locales que tengan necesidades de financiación aunque, de forma excepcional, podrán realizar dichas operaciones si, en el ejercicio presupuestario inmediato anterior, hubieren cumplido con los objetivos de estabilidad presupuestaria y deuda pública y su periodo medio de pago a proveedores no supera en más de treinta días el plazo máximo previsto en la normativa de morosidad.

No obstante, hay que señalar que el legislador no ha delimitado el tipo de sociedades a las que se refiere esta prohibición -como, por otra parte, ha hecho en relación con otras medidas adoptadas en la referida Disposición Adicional Novena-, de tal manera que, de realizarse una interpretación literal del precepto señalado, aquellos municipios en los que concurran las circunstancias anteriores no podrían constituir nuevas sociedades, siendo indiferente la composición de su capital social, es decir, que sean íntegramente públicas o mixtas, y que su objeto social consista en la gestión de servicios públicos o en la realización de actividades económicas. En el caso de las sociedades de economía mixta gestoras de servicios públicos, la interpretación de dicha disposición en el sentido anterior, llevaría al resultado paradójico de que aquellos municipios que tengan en vigor un plan de ajuste o un plan económico financiero no puedan optar por gestionar indirectamente un determinado servicio público empleando esta modalidad contractual que le permitiría captar financiación privada manteniendo el control sobre su funcionamiento.

En tercer lugar, se limita la posibilidad de recurrir a fórmulas societarias para la gestión directa de servicios públicos (art. 85.2 LBRL). Sin embargo, con carácter general, no se establece ningún tipo de limitación al empleo de fórmulas indirectas de gestión de los servicios públicos, en particular, de las sociedades de economía mixta, más allá de las que se puedan derivar de la aplicación de la Disposición Adicional Novena 
REALA. Nueva Época - N. ${ }^{16}$, octubre 2021 - ISSN: 1989-8975 - DOI: https://doi.org/10.24965/reala.i16.10965 - [Págs. 98-117]

¿Es posible crear sociedades de economía mixta para la gestión de servicios públicos locales en el marco de contratos de servicios...

Diana Santiago Iglesias

de la LBRL, a aquellos municipios que tengan en vigor un plan de ajuste o económico financiero, a las que se ha hecho referencia con anterioridad ${ }^{21}$.

\section{REFLEXIÓN FINAL}

Las sociedades de economía mixta gestoras de servicios públicos se configuraban, hasta la entrada en vigor de la LCSP de 2017, como una de las modalidades del contrato de gestión de servicios públicos. La regulación de dicho tipo contractual unida a la libertad de pactos reconocida en el art. 25 del TRLCSP -al amparo de la cual podían constituirse sociedades de economía mixta en el marco de cualquier contrato público, siempre que en los pliegos se introdujese esta condición- evitaron muchos de los problemas existentes en otros países europeos, como Italia, respecto a la fórmula de elección de socio privado o al título de adjudicación de la gestión del servicio a la sociedad mixta de que se trate.

Tras la supresión de dicho contrato, la gestión indirecta de los servicios públicos podrá llevarse a cabo a través del contrato de concesión de servicios o del contrato de servicios, en función de si existe traslación del riesgo operacional al contratista, $\mathrm{y}$, al igual que sucedía bajo la norma anterior, en virtud de la libertad de pactos (art. 34.1 de la LCSP de 2017), en los pliegos del contrato que proceda celebrar podrá introducirse como condición su ejecución a través de una sociedad de economía mixta. Así, la adjudicataria del contrato no sería, en primera instancia, la sociedad, sino el licitador que resulte elegido a condición de que constituya la sociedad de economía mixta en los términos indicados en los pliegos del contrato, acto que irá acompañado de la atribución a la misma de la gestión del servicio público de que se trate, colocándose en una posición asimilada a la del contratista.

En este punto, se plantea la cuestión de cómo encajar dicha regla general con lo dispuesto en la DA 22 de la LCSP de 2017, cuyo alcance puede ser objeto de distintas interpretaciones: una más restrictiva -odiosa sunt restringenda-, que es aquella por la que se ha optado en este trabajo, y otra extensiva, que puede enmarcarse en la línea seguida tanto por el legislador español, que ha transpuesto las directivas de contratación con una rigidez excesiva, que va más allá de lo demandado en las mismas (Baño León, 2018, p. 15), como por muchos operadores jurídicos, que tienden a emplear la misma rigidez en la interpretación del alcance de las normas internas de contratación.

La propuesta defendida en este trabajo consiste en entender que la DA22 de la LCSP de 2017 introduce ciertos límites al empleo de las sociedades de economía mixta aplicables, únicamente, a aquellos supuestos en que éstas se crean en el marco de contratos de concesión de obras y de concesión de servicios, como parece desprenderse de su propio título, y que, esencialmente, se reducen a exigir que la sociedad de economía mixta sea mayoritariamente pública, ya que los demás requisitos a los que se hace referencia en la mencionada disposición adicional se derivan del propio articulado de la LCSP de 2017 y tienen una finalidad, esencialmente, didáctica. A estos límites contenidos en la DA22, habrá que añadir, a su vez, los introducidos por el art. 69 del RDPRTR, aplicables sólo en aquellos casos en que se recurra a una sociedad de economía mixta para la ejecución de contratos de concesión de obras o de concesión de servicios celebrados en el marco proyectos del Plan de Recuperación, Transformación y Resiliencia de la Economía Española.

La lectura de la DA 22 de la LCSP de 2017 que aquí se propone permitiría aprovechar el potencial de las sociedades de economía mixta gestoras de servicios públicos, fórmula que permite mantener un control más estrecho sobre la gestión del servicio de que se trate, contar con el know-how del socio privado e, incluso, lograr beneficios derivados de su gestión más eficiente y eficaz.

\section{REFERENCIAS BIBLIOGRÁFICAS}

Alemany Garcías, J. (2019). Los encargos a sociedades de economía mixta en la actual Ley de Contratos del Sector Público. Revista de Estudios de la Administración Local y Autonómica, 12, 111-125. https://doi.org/10.24965/reala. i12.10704

21 A pesar de que esta medida podría cuestionarse desde el punto de vista del respeto al principio de autonomía municipal y a la potestad de autoorganización de las entidades locales, por los motivos señalados anteriormente, en la STC 41/2016, de 3 de marzo, se ha señalado al respecto que: «desde la perspectiva de los entes locales, el art. 85.2 LBRL condiciona la autonomía local, pero no la vulnera en absoluto. Los entes locales conservan amplios espacios de opción organizativa. No puede ponerse reparos a la previsión de un informe del interventor local que valore la sostenibilidad financiera». En este mismo sentido se había pronunciado, previamente, el Consejo de Estado en su Dictamen 338/2014. 
REALA. Nueva Época - N. ${ }^{16}$, octubre 2021 - ISSN: 1989-8975 - DOI: https://doi.org/10.24965/reala.i16.10965 - [Págs. 98-117]

¿Es posible crear sociedades de economía mixta para la gestión de servicios públicos locales en el marco de contratos de servicios...

Diana Santiago Iglesias

Almeida Cerreda, A., Gómez-Olano González, D. y Sánchez Gallardo, F. J. (2014). Los contratos del sector público: el contrato de gestión de servicios públicos. En M. Yzquierdo Tolsada (dir.), Contratos civiles, mercantiles, públicos, laborales e internacionales, con sus implicaciones tributarias. Thomson Reuters Aranzadi.

Baño León, J. M. (2018). La Ley de Contratos del Sector Público y gestión de lo público ¿Regulación o sobrerregulación? Revista Aragonesa de Administración Pública, 18, 11-19.

Bernal Blay, M. Á. (2010). La colaboración público-privada institucional. Revista Aragonesa de Administración Pública, 37, 93-138.

Boto Álvarez, A. (2014). Redimensionamiento del sector público local. En T. Quintana López (dir.), La reforma del régimen local (pp. 465-518). Tirant Lo Blanch.

Díez Sastre, S. (2020). La acción concertada como nueva forma de gestión de los servicios sanitarios. En A. Agulló Agüero (dir.), Financiación de la sanidad. Tributación, gestión, control del gasto y reparto constitucional del poder financiero (pp. 232-262). Tirant lo Blanch.

Díez Sastre, S. (2021). Contratos «open-house»: comprar sin licitar. Revista de Estudios de la Administración Local y Autonómica. Nueva época. 15, 5-23. https://doi.org/10.24965/reala.i15.10911

Fuentes i Gasó, J. R. (2019). La pervivencia de la gestión indirecta de los servicios públicos locales tras la nueva Ley de Contratos del Sector Público: las sociedades de economía mixta. Cuadernos de Derecho Local, 50, 14-51.

Garrido Juncal, A. (2020). Los servicios sociales en el s. XXI: nuevas tipologías y nuevas formas de prestación. Aranzadi.

Gil Ibáñez, J. L. (2020). Ley de contratos del sector público. Concordancias, jurisprudencia, índice analítico y normativa complementaria. Colex.

Gimeno Feliú, J. M. (2018). El nuevo modelo concesional. Hacia el necesario equilibrio entre lo público y lo privado. El Cronista del Estado Social y Democrático de Derecho, 74, 4-13. https://www.iustel.com/v2/revistas/detalle_revista. asp?id_noticia=419994

Gimeno Feliú, J. M. (2019). Las sociedades de economía mixta. En J. M. Martínez Fernández (coord.), La gestión de los servicios públicos locales en el marco de la LCSP, la LRJSP y la LRSAL. Wolters Kluwer.

Gimeno Feliú, J. M. (15 de febrero de 2021). Los fondos Next Generation y la colaboración público privada (I) [comentario en el blog Pixelware]. https://pixelware.com/los-fondos-next-generation-y-la-colaboracion-publico-privada/.

Gómez-Ferrer Morant, R. (2000). La sociedad privada municipal concesionaria de servicios públicos. En F. Sosa Wagner (coord.), El Derecho Administrativo en el umbral del siglo XXI. Homenaje al Profesor Dr. D. Ramón Martín Mateo (pp. 1895-1904). Tirant lo Blanch.

González-Deleito Domínguez, N. y Carpintero Rodríguez, A. (2019). La posición jurídica del socio privado minoritario en las sociedades de economía mixta. Actualidad administrativa, 10.

Hernández González, F. L. (2016). La controvertida supresión del contrato de gestión de servicios públicos. El Cronista del Estado Social y Democrático de Derecho, 60, 50-57. https://www.iustel.com/v2/revistas/detalle_revista.asp?id_ noticia $=417251$

Hernández González, F. L. (2018). La delimitación de los contratos públicos de servicios y de concesión de servicios. En J. M. Gimeno Feliú (dir.), Estudio Sistemático de la Ley de Contratos del Sector Público (pp. 477-516). Aranzadi Thomson Reuters.

Huergo Lora, A. (2017). El riesgo operacional en la nueva Ley de Contratos del Sector Público. Documentación Administrativa, 4, 31-51. https://doi.org/10.24965/da.v0i4.10494

Laguna de Paz, J. C. (2017). Los contratos administrativos de concesión de servicios y de servicios a los ciudadanos. Revista de Administración Pública, 204, 41-68. https://doi.org/10.18042/cepc/rap.204.02

López de Castro García-Morato, L. y Ortega Bernardo, J. (2021). Los servicios públicos locales. En F. Velasco Caballero (dir.), Tratado de Derecho Local (pp. 471-506). Marcial Pons.

Lazo Vitoria, X. y Noguera de la Muela, B. (2018). Service concessions in Spain. En X. Lazo Vitoria (ed.), Service concessions in the EU a comparative study of the transposition of Directive 2014/23 on the award of concession contracts into national law (pp. 189-214). Aranzadi Thomson Reuters.

Martín-Retortillo Baquer, L. (1961). De la "gestión interesada» a las "cláusulas de interesamiento». Revista de Administración Pública, 36, 67-108. http://www.cepc.gob.es/publicaciones/revistas/revistaselectronicas? IDR=1\&ID $\mathrm{N}=36 \&$ IDA $=22187$

Martínez-Alonso Camps, J. L. (2014). El sector público local: redimensionamiento y gestión de actividades y servicios públicos. En J. A. Carrillo Donaire y P. Navarro Rodríguez (coords.), La reforma del régimen jurídico de la Administración local (pp. 581-659). La Ley.

Martínez López-Muñiz, J. L. (2017). Sentido y alcance de la transposición de las Directivas de la Unión Europea (análisis particular en materia de contratación pública). Revista de Administración Pública, 202, 13-41. https://doi. org/10.18042/cepc/rap.202.01

Menéndez Sebastián, E. M. (2020). El contrato de servicios con prestaciones directas a la ciudadanía como modalidad de gestión indirecta de servicios públicos. Revista de Administración Pública, 212, 375-400. https://doi. org/10.18042/cepc/rap.212.14

Miguez Macho, L. (2016). La distinción entre las concesiones de servicios y otros contratos públicos a la luz de la Directiva 2014/23/UE: repercusiones para el derecho español. En S. Rodríguez Campos (coord.), Las nuevas directivas de contratos públicos y su transposición (pp. 217-233). Marcial Pons. 
REALA. Nueva Época - N. ${ }^{16}$, octubre 2021 - ISSN: 1989-8975 - DOI: https://doi.org/10.24965/reala.i16.10965 - [Págs. 98-117]

¿Es posible crear sociedades de economía mixta para la gestión de servicios públicos locales en el marco de contratos de servicios...

Diana Santiago Iglesias

Montoya Martín, E. (2014). Medidas de redimensionamiento del sector público instrumental local antes y después de la Ley 27/2013, de 27 de diciembre de racionalización y sostenibilidad de la Administración Local. Revista General De Derecho Administrativo, 36, https://www.iustel.com/v2/revistas/detalle_revista.asp?id_noticia=414746\&d=1

Morell Ocaña, L. (1999) La organización y las formas de gestión de los servicios en los últimos cincuenta años. Revista de Administración Pública, 150, 379-412. http://www.cepc.gob.es/publicaciones/revistas/revistaselectronicas?IDR $=1 \&|\mathrm{DN}=148 \&| \mathrm{DA}=24271$

Ortega Bernardo, J. y De Sande Pérez-Bedmar, M. (2016). El debate sobre la remunicipalización de los servicios públicos: aspectos jurídicos, administrativos y laborales. Anuario de Derecho Municipal, 9, 63-96.

Ponce Solé, J. (2016). Remunicipalización y privatización de los servicios públicos y derecho a una buena administración. Análisis teórico y jurisprudencial del rescate de concesiones. Cuadernos de Derecho Local, 40, 68-108.

Rego Blanco, M. D. (2017a). La cooperativa de servicios públicos en Andalucía como modalidad de sociedad de economía mixta local. Revista Andaluza de Administración Pública, 99, 51-88. https://doi.org/10.46735/raap. n99.53

Rego Blanco, M. D. (2017b). Novedades sobre la sociedad de economía mixta en la Ley de Contratos del Sector Público de 2017. Documentación Administrativa. Nueva Época, 4, 151-159. https://doi.org/10.24965/da.v0i4.10502

Ruiz Ojeda, A. (1998). Realidad y régimen jurídico-financiero de la provisión de obras y dotaciones públicas mediante empresa mixta en el ámbito local: la reversión de activos y la remuneración del socio privado. Revista de Estudios de la Administración Local y Autonómica, 278, 101-170. https://doi.org/10.24965/reala.vi278.9005

Santiago Iglesias, D. (2010). Las sociedades de economía mixta como forma de gestión de los servicios públicos locales. lustel.

Santiago Iglesias, D. (2015). Las sociedades municipales ante el Derecho concursal. Anuario de Derecho Concursal, $37,65-112$.

Santiago Iglesias, D. (2017). Empresas locales. En F. Velasco Caballero (dir.), Tratado de Derecho Económico Local (pp. 153-190). Marcial Pons.

Sahún Pacheco, R. (2019). Riesgo operacional y servicio público. BOE.

Tornos Mas, J. (2016). La remunicipalización de los servicios públicos locales. Algunas precisiones conceptuales. El Cronista del Estado Social y Democrático de Derecho, 58-59, 32-49. https://www.iustel.com/v2/revistas/detalle_ revista.asp?id_noticia $=417193$

Villarejo Galende, H. y Calonge Velázquez, A. (2018). Las principales novedades de la nueva ley 9/2017, de 8 de noviembre, de contratos del sector público. Revista Jurídica de Castilla y León, 46, 7-64. https://www.jcyl.es/web/ jcyl/AdministracionPublica/es/Plantilla100Detalle/1215245063566/Publicacion/1284821870851/Redaccion 